\title{
Synthesis and Characterizations of Folate-Conjugated PLGA-PEG Nanoparticles Loaded with Dual Agents ${ }^{\dagger}$
}

\author{
Yüksel Öğünç ${ }^{1}$, Müzeyyen Demirel ${ }^{2}$ and Zerrin Seller 1,* \\ 1 Department of Biochemistry, Faculty of Pharmacy, Anadolu University, Tepebaş1 26470, Turkey \\ 2 Department of Pharmaceutical Technology, Faculty of Pharmacy, Anadolu University, \\ Tepebaşı 26470, Turkey \\ * Correspondence: zseller@anadolu.edu.tr; Tel.: +90-2223-350-580 (ext. 3722) \\ + Presented at the 2nd International Conference on Natural Products for Cancer Prevention and Therapy, \\ Kayseri, Turkey, 8-11 November 2017.
}

Publish: 14 November 2017

\begin{abstract}
The purpose of this study is that the formulation and characterization of folate-conjugated poly(lactide-co-glycolide)-block-poly(ethyleneglycol)(PLGA-PEG-Folate) nanoparticles loaded with the dual agents; vincristine sulfate(VS) and $\varepsilon$-viniferine(EV). Folate-conjugated nanoparticles are useful vehicles to facilitate active targeting of varies chemotherapeutic agents to cancer cells. PLGA-PEG-folate was synthesized four stages; folic acid activation, PLGA activation, synthesis of folate-PEG-NH $\mathrm{H}_{2}$ and synthesis of PLGA-PEG-folate conjugate copolymer. Characterization of the conjugates was performed using FTIR and H-NMR. Drug loaded nanoparticles was prepared by the nanoprecipitation method. After the formulation of nanoparticles, particle size, polydispersity index and zeta potential were measured using both non-lyophilise and lyophilise formulations. The results were found to be $82.76 \pm 22.42 / 342.2 \pm 20.7 \mathrm{~nm}, 0.311 \pm 0.015 / 0.394 \pm 0.04$ and $-8.33 \pm 3.68 / 8.05$ $\pm 1.69 \mathrm{mV}$ respectively. The drug-loading percentages were found to be $8.87 \pm 0.68$ and $2.60 \pm 0.20$ (mean \pm SE) for EV and VS, respectively. The free EV was found about $12.00 \%$ and $\mathrm{EV}$ release from nanoparticles was determined $31.83 \%$ at $6 \mathrm{~h}$. In the other hand, VS release did not occur from nanoparticles while free VS reached $100 \%$ in same duration. These results suggest that VS and EV loaded PLGA-PEG-folate nanoparticles could be potential delivery system for targeting the drugs to cancer cells. Therefore, in vitro studies with these nanoparticles are already carrying out in our laboratory using varies cancer cells.
\end{abstract}

Keywords: Nanoparticle; PLGA-PEG-Folate; Vincristine sulfate

Acknowledgment: This study was financed by Anadolu University Scientific Research Project Foundation (No: 1406S313).

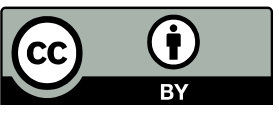

(C) 2017 by the authors. Licensee MDPI, Basel, Switzerland. This article is an open access article distributed under the terms and conditions of the Creative Commons Attribution (CC BY) license (http://creativecommons.org/licenses/by/4.0/). 